\title{
CONTROL OF THE SOIL-INHABITING GRUBS OF PUERTO RICO ${ }^{1}$
}

\section{GEORGE N. WOLCOTT²}

The roots of agricultural crops in Puerto Rico are attacked by two kinds of soil-inhabiting grubs, either one of which may cause an immense amount of damage if present in appreciable numbers. The common white grubs of the coastal regions are the immature stage of the May beetles or "caculos", described by Mr. E. G. Smyth as Phyllophaga portoricensis and P. vandinei. They have six legs, and their bodies are bent double, so that the hind end is opposite the powerful jaws with which they eat the roots of plants.

The grub of the "vaquita" has an oval body, and as it possesses no legs, progress thru the soil depends on its rapid powerful muscular contractions. The injury which these legless grubs cause to a plant is mainly from their habit of burrowing to the inside of its subterranean portion, and feeding on its interior. Apparently they are quite as omnivorous in their feeding habits as are white grubs, having been noted attacking the roots of weeds and forest trees, such as mahogany seedlings in nurseries, as well as those of economic plants. White grubs attacking sugar-cane first eat the rootlets and then chew into the root-stalk, but vaquita grubs when growing most rapidly burrow inside the root-stalk and feed within. They have thus received the name of sugar-cane weevil root-stalk borer, the adults being the striped weevils scientifically known as Diaprepes abbreviata (Linnaeus).

Despite very heavy larval mortality, survival in sufficient numbers to be a very serious economic pest is assured by the five thousand (more or less) eggs which are laid by the female weevil (Wolcott 1936). The legless little grubs, which hatch seven days after:oviposition, appear to have a very tenuous hold on existence, for despite their vigor and constant activity, few of them even attempt to eat, and of the survivors, growth before transformation to second instar is slow as compared with that in the instars immediately following. In the first, second and third instars, the grubs feed on very small roots or on root hairs, showing little or none of the tendency to burrow into the larger roots which appears in the fourth instar. That is, up to the beginning of the fourth instar, they are free-moving in the soil, completely unprotected against any toxic substance which may be present. Thus if any grubs survive in soil to which toxicants have been added, their survival proves that the chemical is not present in sufficient amount to cause mortality.

After the beginning of the fourth instar and up to the time that the

${ }^{1}$ Presented at the Sixty-Second Annual Meeting of the American Association of Economic Entomologists, December 18-21, 1950 at Denver, Colorado.

2 Entomologist, Head of Department. 
grubs have attained full size, they are increasingly protected against the effect of any chemical in the soil by their habit of burrowing inside the grain of corn, or root-stalk of sugar-cane, or comparatively large root or corm or tuber of any plant within which and upon which they may be feeding. In the diapause period before pupation, when they vigorously burrow about thru the soil without any apparent purposes, they are again fully exposed to the action of any insecticidal chemical that may be present in the soil, but naturally during this period of their life-history are much more resistant to extraneous chemicals than as just-hatched or very small grubs.

Laboratory experiments conducted with large or fully-grown Diaprepes grubs in the same soil and paralleling similar tests with third (last) instar white grubs of Phyllophaga portoricensis Smyth and P. vandinei Smyth, in their susceptibility to several of the newer insecticides, gave most inconclusive and indeed at times quite contradictory results. The tests with the third instar white grubs made possible very definite recommendations as to the effective amount per acre to be applied of aldrin (Hyman 118), the gamma isomer of benzene hexachloride (lindane), rhothane or DDD, and DDT (Wolcott 1950). Even after being mixed with the soil for a year both aldrin and lindane showed little or no decrease in toxicity to white grubs, indicating that field applications at the rate of as little as two pounds per acre should result in commercial control of this pest.

By comparison, the tests with Diaprepes grubs were so unsatisfactory as to suggest that the resistance to chemicals of these grubs in the diapause or pre-diapause stage is ever so much greater than of other grubs of approximately the same size which are still eating and growing. To attain some degree of uniformity, all grubs being tested should be in the same instar, presumably insuring that they have approximately the same susceptibility to toxic substances. The most obvious way of starting with all grubs in the same instar is to use those which have just hatched. If, despite high larval mortality due to natural causes, some of these can be reared to fourth instar (at which time they cease to be subject to the effect of chemicals mixed with the soil because of their habit on burrowing within the host), this furnishes quite definite proof of the lack of toxicity of the chemical at that rate of concentration in the soil. Admittedly this begs the question of control of large grubs, but as they have already caused most of the injury possible, their destruction is really not as important as that of killing the small grubs before they have begun to burrow into the roots of sugar-cane or other crop.

Oviposition by females of Diaprepes abbreviata occurs during every month in the year, reaching a maximum during May and June, but because of high parasitism by Tetrastichus haitiensis Gahan during these months, 
it is doubtful if many more grubs reach the soil at this time than when egg-clusters are less numerous. The result is a more or less constant reinfestation of the soil, with no well-defined season when maximum injury from the grubs may be anticipated, to prevent which a toxicant might be applied to the soil. Moreover, few cane growers would thus anticipate damage by Diaprepes grubs, but might be expected to apply insecticides after injury had begun to be noticeable, and the specific grubs causing it had already reached their diapause stage. Thus the residual effect of the chemical on the just-hatched grubs for some months or years after application to the soil will indicate a more practical method of keeping the soil free of grubs for an extended period, especially if the insecticide is also toxic to white grubs for an equally long time. This extended explanation is given that it may be apparent why the tests about to be described were conducted, and why the methods adopted were used.

One ounce tin salve boxes, and later two ounce tin salve boxes, were filled with earth from the much larger cans in which the tests had been conducted with white grubs, in each of which cans the amount of insecticide mixed with the soil was computed on the basis of field applications of pounds per acre. As this soil had been most thoroly mixed with the insecticide originally, and had been repeatedly mixed subsequently every time the large cans were dumped for determination of white grub mortality and and for replanting with corn, cucumbers and/or papayas, the small samples of earth extracted for test with the just-hatched Diaprepes grubs in the salve boxes may be considered typical. In every case, the results obtained with Diaprepes grubs were consistent with each other, indicating that even these small samples contained the proper proportion of insecticide. One grain of corn and four cucumber seeds were planted in the earth in each one ounce salve box, and in the two ounce tins, four grains of corn. Water was added with a medicine dropper so that the soil would be of optimum moisture content both for the germination of the seeds and for the survival of the grubs. Each day for a week, approximately equal numbers of the Diaprepes grubs which had hatched in the preceding 24 hours were placed on the surface of the soil in each salve box. In the later tests, all grubs that hatched in the preceding 24 hours were placed in the cans with earth mixed with different dilutions of only one chemical, that the date of starting the test might be the same for all. Howerer, to make sure that conditions would be equal for all, subsequent additions might be made when the earth had dried somewhat as the corn germinated. At weekly intervals, or oftener if the corn seedlings tended to push up the cover of the salve box, the entire contents was dumped, the presence or absence of grubs noted, their growth and stage of development as indicated by head-size, and grubs and soil replaced, with fresh seeds and an appropriate amount of water 
added. The tests terminated when at least one grub had reached fourth instar, as indicated by the size of its head capsule, as well as by its change of habit of burrowing into the grain of corn rather than continuing to feed on the roots and root-hairs.

\section{RESULTS}

In the winter rearing experiments (November 1949 to January 1950), by the 27 th day after hatching no live grubs could be found in the earth containing 0.5 aldrin, and by the 41 st day, no live grubs could be found in the earth with $1 \mathrm{lb}$. per acre of aldrin (Hyman 118). However, one grub in 4th instar, transferred from $1 \mathrm{lb}$. gamma isomer to $1 \mathrm{lb}$. Hyman 118, did survive for over two weeks, feeding in the corn grain, but having transformed to 5th instar, was dead by the end of the third week. The only other test resulting in the mortality of the grubs was that containing 10 lbs. per acre of rhothane (DDD), of which some grubs reached 2nd instar 33 days after hatching, but all were dead and covered with spores of the green Muscardine (Metarrhizium anisopliae) by the 41st day.

In the winter rearing tests, grubs had transformed to 4th instar by the $33 \mathrm{~d}$ day in the cane containing earth mixed with $1 \mathrm{lb}$. of gamma isomer per acre, and with $1 \mathrm{lb}$. and $2 \mathrm{lbs}$. of chlordan. By the 41st day, grubs had transformed to 4th instar in $2 \mathrm{lbs}$. of gamma isomer per acre, in $10 \mathrm{lbs}$. of DDT per acre, and in the check. After 47 days, grubs had transformed to 4th instar in earth containing $10 \mathrm{lbs}$. per acre of methoxychlor, $10 \mathrm{lbs}$. of zine dimethyldithiocarbamate, 10 lbs. CPR (U. S. Industrial Chemicals), and $10 \mathrm{lbs}$. of ryania.

The poor showing of some of these chemicals was not unanticipated, as they had been similarly ineffective against white grubs. But the gamma isomer of benzene hexachloride had been almost as effective as aldrin in killing white grubs, and in May 1950 another series of tests was started to determine the concentration at which gamma isomer would be toxic. As in the winter tests, but more rapidly because of somewhat higher temperatures, all the grubs died in the cans containing earth mixed with aldrin (Hyman 118) at 5 lbs., 2 lbs., $1 \mathrm{lb}$. and $0.5 \mathrm{lb}$. per acre, none being noted after the second week. By the 16th day, no live grubs could be found in the earth containing $10 \mathrm{lbs}$. of chlordan per acre, and by the 20 th day none in the earth with $5 \mathrm{lbs}$. of chlordan. However, some grubs in the $1 \mathrm{lb}$. per acre chlordan had successfully transformed to 4 th instar by the 20 th day after hatching; by the 32nd day, some had reached 4th instar in the earth containing $2 \mathrm{lbs}$. chlordan per acre.

During the summer rearing tests, some grubs were still alive in 2nd instar by the 19th day after hatching in the earth containing $25 \mathrm{lbs}$. and 20 lbs. of DDT per acre, but by the 29th day all were dead. 
By the 24th day after hatching, grubs in the earth containing $1 \mathrm{lb}$. per acre of gamma isomer of benzene hexachloride had transformed to 4th instar; by the 31st day, six grubs had reached 4th instar in the earth containing 5 lbs. of gamma isomer per acre, and by the 38th day, one grub had reached 4 th instar in the earth with $10 \mathrm{lbs}$. of gamma isomer per acre.

\section{CONCLUSION}

Gamma isomer of benzene hexachloride is almost as effective in killing third instar white grubs (Phyllophaga spp.) in Puerto Rico as is aldrin (Hyman 118), applications of either at the rate of 2 lbs. per acre resulting in commercial control. It is much inferior in causing the mortality of justhatched weevil grubs of Diaprepes abbreviata L., in laboratory tests, merely delaying the rapidity of development at $10 \mathrm{lbs}$. per acre. Aldrin in all tests killed all Diaprepes grubs at one-twentieth of this concentration, at 0.5 lbs. per acre.

As neither the amount of gamma isomer necessary to kill Diaprepes grubs, nor the maximum amount of aldrin in soil in which they can survive was determined, the disparity in effectiveness of the two insecticides is even greater than these tests indicate.

\section{LITERATURE CITED}

Wolcotr, G. N. 1936. The Life History of Diaprepes abbreviatus L. at Río Piedras, P. R. Jour. Agr. Univ. P. R., 20 (4) : 883-914, fig. ref. 21.

Wolcotr, G. N. 1950. The Chemical Control of White Grubs in Puerto Rico. Seventh Congress, International Society of Sugar Cane Technologists, August-September 1950, Queensland, Australia. 